\begin{tabular}{|c|c|c|}
\hline \multirow{2}{*}{$\begin{array}{r}\text { Case Reports in } \\
\text { Gastroenterology }\end{array}$} & \multicolumn{2}{|c|}{ Case Rep Gastroenterol 2017;11:348-351 } \\
\hline & $\begin{array}{l}\text { DOI: } 10.1159 / 000475918 \\
\text { Published onlıne: May 22, } 2017\end{array}$ & $\begin{array}{l}\text { (c) } 2017 \text { The Author(s) } \\
\text { Published by S. Karger AG, Basel } \\
\text { www.karger.com/crg }\end{array}$ \\
\hline & \multicolumn{2}{|c|}{$\begin{array}{l}\text { This article is licensed under the Creative Commons Attribution-NonCommercial } 4.0 \\
\text { International License (CC BY-NC) (http://www.karger.com/Services/OpenAccessLicense). } \\
\text { Usage and distribution for commercial purposes requires written permission. }\end{array}$} \\
\hline
\end{tabular}

\title{
A Symptomatic Coffee Bean: Acute Sigmoid Volvulus
}

\author{
Michael Scharl Luc Biedermann \\ Division of Gastroenterology and Hepatology, University Hospital Zurich, \\ Zurich, Switzerland
}

\section{Keywords}

Acute sigmoid volvulus $\cdot$ Sigmoid colon $\cdot$ Colonoscopy

\begin{abstract}
An acute sigmoid volvulus is due to the torsion of the sigmoid colon around its mesenteric axis. It mainly occurs in elderly patients and represents an abdominal emergency requiring urgent treatment. A 53-year-old male patient with severe craniocerebral injury and traumatic subarachnoidal bleeding 3 weeks prior presented on the ward with distended abdomen without abdominal pain, muscular defense, or resistances. He featured large volume diarrhea within the last few hours without signs of bleeding. A plain abdominal X-ray demonstrated a coffee bean sign indicating a sigmoid volvulus. A consequent CT scan of the abdomen revealed a deep outlet obstruction with massively dilated, elongated and twisted loop of the sigmoid colon and no signs of perforation. We performed emergency colonoscopy under the assumption of an acute sigmoid volvulus. After careful insertion of the endoscope completely refraining from insufflation of air or $\mathrm{CO}_{2}$, endoscopic reposition of the sigma could be achieved and a colonic drainage was placed over an inserted guide wire up to the proximal transverse colon. No relapse occurred and a diagnostic colonoscopy after 4 weeks revealed no tumor or polyps. Our report describes a classic case of acute sigmoid volvulus and undermines the potential of colonoscopy as conservative primary treatment of choice.
\end{abstract}




\section{Case Reports in \\ Gastroenterology}

Case Rep Gastroenterol 2017;11:348-351

DOI: $10.1159 / 000475918$

(c) 2017 The Author(s). Published by S. Karger AG, Basel www.karger.com/crg

Scharl and Biedermann: A Symptomatic Coffee Bean: Acute Sigmoid Volvulus

\section{Introduction}

Acute sigmoid volvulus is an abdominal emergency and represents the third most common cause of large bowel obstruction in adults [1]. It usually occurs in elderly men with a mean age between 56 and 77 years [2]. Among the risk factors are chronic constipation, diabetes, neurological disorders, and previous abdominal surgery [3, 4]. Colonoscopic detorsion represents a safe and efficient first-line treatment in stable patients. In patients with low risk for surgery, prophylactic elective sigmoid resection may be performed to prevent recurrent volvulus [5]. The latter appears to be a frequent occurrence in up to two thirds of patients with intended exclusive conservative treatment approach, occurring often relatively short after the initial event (at a median of 31 days in a retrospective study with 57 patients from New Zealand) [6]. In this study, there was no recurrence of volvulus in those patients having undergone surgery. However, when endoscopy is not successful or in case of lifethreatening complications, such as peritonitis, bowel ischemia, gangrene or perforation, emergency surgery is required [3]. This is often the case in multimorbid patients. Additionally, in such patients mortality and recurrence rates are high, up to 20 and $60 \%$, respectively $[5,7]$. Since those patients also often display a high risk for morbidity and mortality in the perioperative setting, sigmoid resection often cannot be conducted $[2,8]$. In this case, percutaneous endoscopic colopexy (PEC) might be a valuable option [9].

Routinely, the diagnosis of acute sigmoid volvulus is established by clinical and radiological findings. From a clinical perspective, sudden abdominal pain, abdominal tenderness, asymmetric abdominal distension, constipation, abdominal tympany, abnormal bowel sounds, and a palpable abdominal mass are amongst the most prevalent initial symptoms and signs [2]. A CT scan is often unnecessary, since a plain X-ray is diagnostic in 57-90\% of patients $[10,11]$. The classical sign of an acute sigmoid volvulus in plain X-rays is the "coffee bean sign", while in an abdominal CT scan, the characteristic "whirl sign" as well as an dilated colon with air/fluid level can be detected $[11,12]$. Those radiologic findings are due to the torsion of the often long and redundant sigmoid colon around its elongated mesenteric axis what finally causes intestinal obstruction [13].

\section{Case Report}

Here, we report the case of a 53-year-old male patient that initially underwent emergency surgery after a fall followed by craniocerebral injury and subdural hematoma. Osteoplastic craniotomy was performed and the subdural hematoma was evacuated. Postoperatively, there was a complicated disease course with septic shock and acute respiratory distress syndrome. Twenty-one days after first cranial surgery, a second craniotomy was performed due to recurrent and progressive subdural hematoma. The next day after surgery, the patient presented on the ward with distended abdomen without abdominal pain, tenderness on palpation, defense, or resistances. He featured large volume diarrhea within the last few hours without signs of bleeding. Body temperature was $38.5^{\circ} \mathrm{C}$, blood pressure was $110 / 70 \mathrm{~mm} \mathrm{Hg}$, and pulse rate was $89 \mathrm{bpm}$. A plain abdominal X-ray demonstrated a clearly distended left colon with coffee bean sign suggesting sigmoid volvulus (Fig. 1). CRP levels rose from $49 \mathrm{mg} / \mathrm{L}$ to $100 \mathrm{mg} / \mathrm{L}$ overnight and leukocytes from 11.06 to $12.45 \mathrm{~g} / \mathrm{L}$. A consequent CT scan of the abdomen revealed a deep outlet obstruction with massively dilated, elongated and twisted loop of sigmoid colon and no signs of perforation. The advice from the 
Scharl and Biedermann: A Symptomatic Coffee Bean: Acute Sigmoid Volvulus

consultant visceral surgeons was emergency endoscopic decompression due to acute sigmoid volvulus.

We performed emergency colonoscopy on the intubated patient. After careful insertion of the colonoscope completely refraining from insufflation of air or $\mathrm{CO}_{2}$ up to the eye of the volvulus, we dilated carefully the sigmoid by gently pushing the tip of the endoscope forward with very cautious air insufflation. Hereby, reposition of the sigma was successfully achieved and a colonic drainage was placed over an inserted guide wire. A plain X-ray after the endoscopy showed an obvious and striking regression of the dilated colonic segment and proper placement of the colon drainage in the right lower abdominal quadrant. After endoscopy, there was an uncomplicated disease course, and the patient was discharged after 3 days. No relapse occurred and a diagnostic colonoscopy after 4 weeks revealed no signs of tumor or polyps. The patient was seen after 3 weeks and 4 months in the surgical outpatient clinic. The decision was made to refrain from the designated surgical intervention.

\section{Discussion}

Our report describes a classic case of an acute sigmoid volvulus and illustrates the place of colonoscopy as conservative primary treatment of choice. It has been shown that emergency surgery should only be performed when primary endoscopic intervention is not successful or if peritonitis is present [3]. Recent studies demonstrated that the success rate of primary endoscopic decompression is very high and up to $95 \%[3,9]$.

However, recurrence after successful endoscopy occurs in about one fourth of patients [3] and may be considerably higher up to even two thirds of patients. Accordingly, prophylactic treatment by sigmoid resection with primary anastomosis should be considered, since it also has been shown to represent a very safe procedure in low risk patients (ASA score <3) [9]. Our patient initially rejected sigmoid resection and due to the 4-month follow-up without any further symptoms of recurrence, surgery was finally not conducted.

In summary, our report described the routine treatment of acute sigmoid volvulus by endoscopic decompression. Since no signs of peritonitis or intestinal ischemia were detected, no surgery was performed in the emergency situation, which is in line with the literature.

\section{Statement of Ethics}

The patient agreed with the publication of this case report after informed consent.

\section{Disclosure Statement}

The authors have no conflicts of interest and no funding to disclose.

\section{References}

1 Ballantyne GH, et al: Volvulus of the colon. Incidence and mortality. Ann Surg 1985;202:83-92.

$\checkmark 2$ Atamanalp SS, Ozturk G: Sigmoid volvulus in the elderly: outcomes of a 43-year, 453-patient experience. Surg Today 2011;41:514-519.

3 Lou Z, et al: Appropriate treatment of acute sigmoid volvulus in the emergency setting. World J Gastroenterol 2013;19:4979-4983. 


\section{Case Reports in \\ Gastroenterology}

\begin{tabular}{l|l}
\hline Case Rep Gastroenterol 2017;11:348-351 \\
\hline DOI: 10.1159/000475918 & $\begin{array}{l}\text { ○ 2017 The Author(s). Published by S. Karger AG, Basel } \\
\text { www.karger.com/crg }\end{array}$ \\
\hline
\end{tabular}

Scharl and Biedermann: A Symptomatic Coffee Bean: Acute Sigmoid Volvulus

4 Mulas C, et al: Management of colonic volvulus. Experience in 75 patients. Rev Esp Enferm Dig 2010;102:239-248.

5 Grossmann EM, et al: Sigmoid volvulus in Department of Veterans Affairs Medical Centers. Dis Colon Rectum 2000;43:414-418.

6 Yassaie 0, Thompson-Fawcett M, Rossaak J: Management of sigmoid volvulus: is early surgery justifiable? ANZ J Surg 2013;83:74-78.

7 Brothers TE, Strodel WE, Eckhauser FE: Endoscopy in colonic volvulus. Ann Surg 1987;206:1-4.

8 Safioleas M, et al: Clinical considerations and therapeutic strategy for sigmoid volvulus in the elderly: a study of 33 cases. World J Gastroenterol 2007;13:921-924.

-9 Bruzzi M, et al: Management of acute sigmoid volvulus: short- and long-term results. Colorectal Dis 2015;17:922-928.

10 Osiro SB, et al: The twisted colon: a review of sigmoid volvulus. Am Surg 2012;78:271-279.

11 Burrell HC, et al: Significant plain film findings in sigmoid volvulus. Clin Radiol 1994;49:317-319.

12 Hirao K, et al: Sigmoid volvulus showing “a whirl sign” on CT. Intern Med 2006;45:331-332.

13 Alatise OI, et al: The role of the anatomy of the sigmoid colon in developing sigmoid volvulus: a crosssectional study. Surg Radiol Anat 2013;35:249-257.

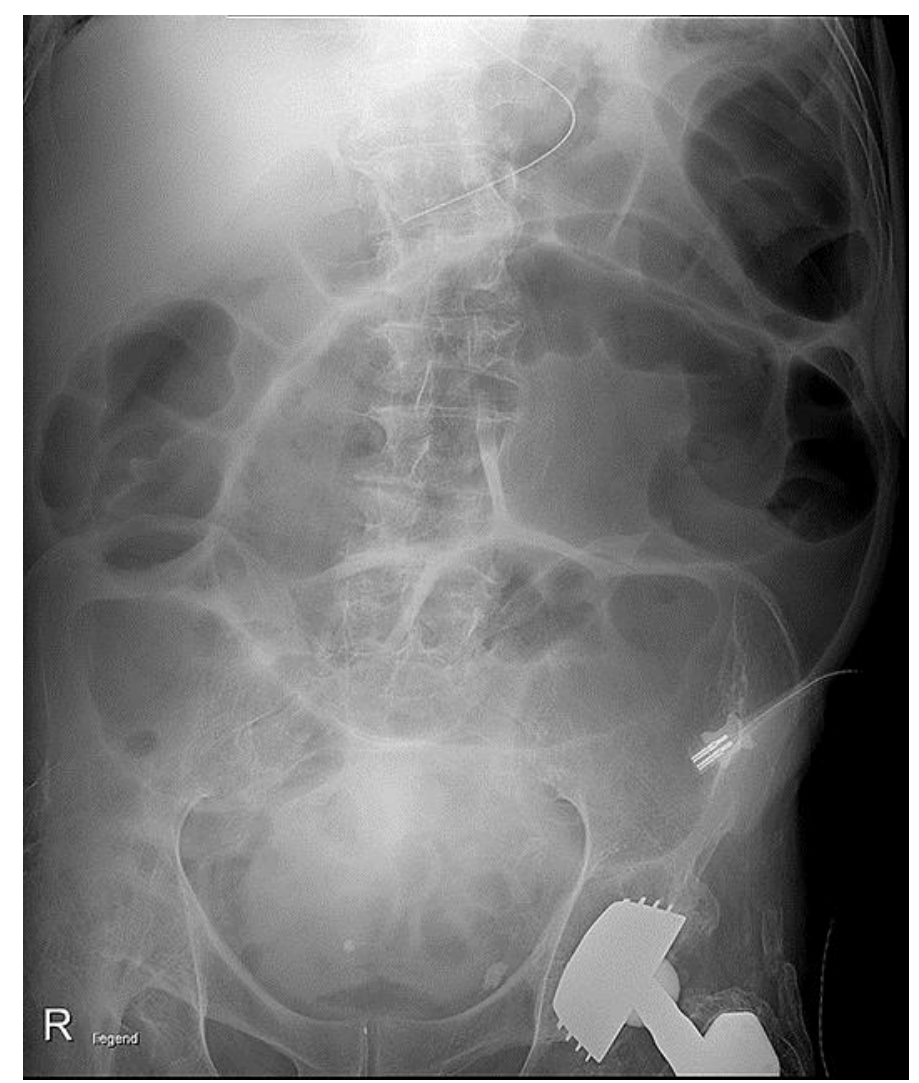

Fig. 1. Plain abdominal X-ray. Image depicting the sigmoid volvulus indicating the typical coffee bean sign. 